\title{
Predicting Typhoon Induced Storm Surges Using the Operational Ocean Forecast System
}

\author{
Sung Hyup You* \\ Global Environment System Research Laboratory, National Institute of Meteorological Research/KMA, \\ Seoul 156-720, Korea
}

Received 22 August 2008, accepted 18 March 2009

\begin{abstract}
This study was performed to compare storm surges simulated by the operational storm surges/tide forecast system (STORM : Storm surges/Tide Operational Model) of the Korea Meteorological Administration (KMA) with observations from 30 coastal tidal stations during nine typhoons that occurred between 2005 and 2007. The results (bias) showed that for cases of overestimation (or underestimation), storm surges tended to be overestimated (as well as underestimated) at all coastal stations. The maximum positive bias was approximately $6.92 \mathrm{~cm}$ for Typhoon Ewiniar (2006), while the maximum negative bias was approximately $-12.06 \mathrm{~cm}$ for Typhoon Khanun (2005). The maximum and minimum root mean square errors (RMSEs) were 14.61 and $6.78 \mathrm{~cm}$, which occurred for Typhoons Khanun (2005) and Usagi (2007), respectively. For all nine typhoons, total averaged RMSE was approximately $10.2 \mathrm{~cm}$. Large differences between modeled and observed storm surges occurred in two cases. In the first, a very weak typhoon, such as Typhoon Khanun (2005), caused low storm surges. In the other, exemplified by Typhoon Nari (2007), there were errors in the predicted typhoon strength used as input data for the storm surge model.
\end{abstract}

Key words : STORM, KMA, Typhoon, Bias, RMSE

Citation: You, S. H., 2010: Predicting typhoon induced storm surges using the operational ocean forecast system. Terr. Atmos. Ocean. Sci., 21, 99-111, doi: 10.3319/TAO.2009.03.18.02(IWNOP)

\section{INTRODUCTION}

Natural disasters, including heavy rain and strong wind, associated with typhoons affect the Korean Peninsula during the summer typhoon season. Various oceanographic systems interact along the coast of Korea, which has a complex coastline and a high tidal range. With increasing property development along Korea's coastal regions, storm surge damage is becoming an important concern and accurate forecasting is crucial. Over the past 37 years (1971 2007) an average of 26 typhoons per year have originated in the northwestern Pacific Ocean, among which three on average have affected the Korean Peninsula (KMA 2005; Cha et al. 2007, 2008).

The Korean Peninsula is bounded by the Yellow Sea, East China Sea, and East/Japan Sea. This complex oceanographic system includes large tides in the Yellow Sea and

\footnotetext{
* Corresponding author

E-mail:shyou@kma.go.kr
}

seasonally varying monsoon and typhoon events. For Korea's coastal regions, floods caused by typhoon-induced storm surges are among the most serious threats. To protect lives and property, accurate forecasting of storm surges is essential.

Researchers have studied storm surges around Korea using data analysis (Hwang 1971; Chu 1987; Oh et al. 1988) and numerical modeling (Choi 1986; Oh and Kim 1990; Hong and Yoon 2003) methods. Although previous studies have shown good reproduction of typhoon-induced storm surges, these studies have been hindcasts rather forecasts. Furthermore, previous modeling studies have used indirect methods to obtain sea wind and air pressure fields (e.g., from weather charts and simple models).

The National Institute of Meteorological Research (NIMR)/Korea Meteorological Administration (KMA) developed an operational storm surge model with horizontal resolution of $1 / 12^{\circ}$ in 2005 (You et al. 2005). This socalled Storm surge/Tide Operational Model (STORM) has 
been applied as a formal operational forecasting tidal/storm surge model since July 2006, after 1 year of testing from June 2005.

In this study, we applied STORM to predict storm surges induced by nine typhoons that affected Korea between 2005 and 2007. We compared the modeled surges with in situ observations from tidal stations around the coastal region of Korea.

\section{METHODS}

STORM used in this study was based on the Princeton Ocean Model (POM), a primitive general ocean circulation model described by Mellor (1998). From POM, we made a two-dimensional depth-integrated tide and storm surges model with an Arakawa C-grid system. The amplitudes and phases of the tidal constituents of the open boundary condition are taken from eight constituents $\left(\mathrm{M}_{2}, \mathrm{~S}_{2}, \mathrm{~K}_{1}, \mathrm{O}_{1}, \mathrm{~K}_{2}, \mathrm{P}_{1}\right.$, $\mathrm{N}_{2}$, and $\mathrm{Q}_{1}$ ) described by Matsumoto et al. (2000). The model covers the northwestern Pacific Ocean from $115^{\circ}-150^{\circ} \mathrm{E}$, $20-52^{\circ} \mathrm{N}$ (Fig. 1). The horizontal grid intervals are $1 / 12^{\circ}$ in both latitudinal and longitudinal directions. The model bottom topography is based on the National Geophysical Data Center ETOPO5 data with 5-min resolution.

Vertically integrated equations for tides and storm surges incorporate bottom friction using nonlinear advective terms. The equations are given as:

$\frac{\partial \eta}{\partial t}+\frac{\partial}{\partial x}(\bar{U} D)+\frac{\partial}{\partial y}(\bar{V} D)=0$

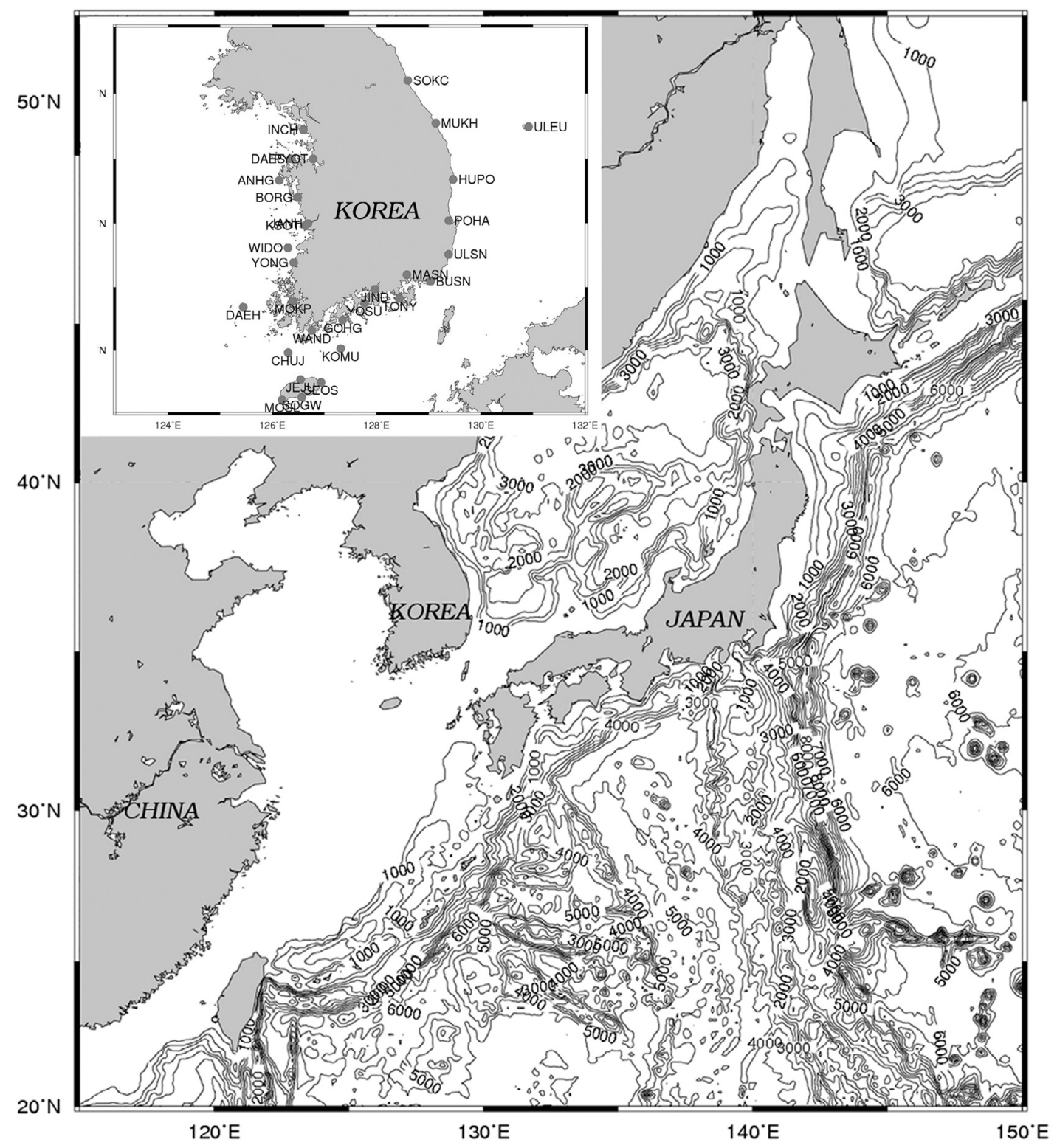

Fig. 1. Modeled area with topography and locations of the selected coastal stations (small figure). 


$$
\begin{aligned}
& \frac{\partial}{\partial t}(\bar{U} D)+\frac{\partial}{\partial x}\left(\overline{U^{2}} D\right)+\frac{\partial}{\partial y}(\bar{U} \bar{V} D) \\
&=\tilde{F}_{x}+f \overline{V D}-g D \frac{\partial\left(\eta-\eta_{0}\right)}{\partial x}-\tau_{x s}+\tau_{x b} \\
& \frac{\partial}{\partial t}(\bar{V} D)+\frac{\partial}{\partial x}(\bar{U} \bar{V} D)+\frac{\partial}{\partial y}\left(\overline{V^{2}} D\right) \\
&=\tilde{F}_{x}+f \overline{U D}-g D \frac{\partial\left(\eta-\eta_{0}\right)}{\partial y}-\tau_{y s}+\tau_{y b}
\end{aligned}
$$

where $x$ and $y$ are east longitude and north latitude, respectively, $t$ is time, $g$ is acceleration due to gravity, $\eta$ is sea surface elevation, $D$ is total water depth $(=H+\eta)$, and $H$ is the undisturbed water. $\bar{U}$ and $\bar{V}$ are the components of the depth-mean current given by:

$\bar{U}=\int_{-H}^{\eta} u d z, \quad \bar{V}=\int_{-H}^{\eta} v d z$

The quantities $\tilde{F}_{x}$ and $\tilde{F}_{y}$ are defined as follows:

$$
\begin{aligned}
& \tilde{F}_{x}=\frac{\partial}{\partial x}\left(2 A_{M} D \frac{\partial \bar{U}}{\partial x}\right)+\frac{\partial}{\partial y}\left[A_{M} D\left(\frac{\partial \bar{U}}{\partial y}+\frac{\partial \bar{V}}{\partial x}\right)\right] \\
& \tilde{F}_{y}=\frac{\partial}{\partial y}\left(2 A_{M} D \frac{\partial \bar{V}}{\partial y}\right)+\frac{\partial}{\partial x}\left[A_{M} D\left(\frac{\partial \bar{U}}{\partial y}+\frac{\partial \bar{V}}{\partial x}\right)\right]
\end{aligned}
$$

where $A_{M}$ is the horizontal diffusivity determined by Smagorinsky-type diffusivity [Eq. (7)] in the model.

The Smagorinsky formula is:

$$
A_{M}=C \Delta x \Delta y \frac{1}{2}\left|\nabla \bar{V}+(\nabla \bar{V})^{T}\right|
$$

where $\Delta x$ and $\Delta y$ are the grid sizes in the longitudinal and latitudinal directions, respectively, and $\nabla \bar{V}$ is the horizontal gradient of velocity. Values of $C$ (the HORCON lateral friction parameter) in the range of 0.10 to 0.20 seem to work well. In this study, we used a value of 0.10 .

The surface boundary condition $\left(\tau_{x s}, \tau_{t s}\right)$ in Eqs. (8) and (9) was determined by sea wind stress curl from the Regional Data Assimilation Prediction System (RDAPS) of the KMA. $\eta_{0}$ in Eqs. (2) and (3) is originated from the effect of atmospheric pressure and the relation is $\rho g \eta_{0}=-\left(P_{s}-1010\right)$. $P_{s}$ is the surface pressure of atmosphere from RDAPS.

The bottom stress condition $\left(\tau_{x s}, \tau_{t s}\right)$ is given as:

$\tau_{x b}=C_{d} \bar{U} \sqrt{\overline{U^{2}}+\overline{V^{2}}}$

$\tau_{y b}=C_{d} \bar{V} \sqrt{\overline{U^{2}}+\overline{V^{2}}}$
$C_{d}=\operatorname{MAX}\left\{\frac{k^{2}}{\left[\log \left(h / z_{0}\right)-1\right]^{2}}, C_{\max }\right\}$

where $C_{d}$ is the coefficient of the bottom friction with a maximum value of approximately $0.0025, k$ is the von Karman coefficient $(=0.4)$, and $z_{0}$ is the roughness coefficient $(=0.0005)$.

To solve Eqs. (1), (2), and (3), a radiation condition for the open boundaries is used to prevent the artificial reflection of disturbances generated in the model. The open boundary condition is specified as follows:

$\overline{U_{0}}=\frac{\sqrt{g h}}{h}\left(\eta-\eta_{0}\right)$
$\overline{V_{0}}=\frac{\sqrt{g h}}{h}\left(\eta-\eta_{0}\right)$

$\eta_{0}(i, j, t)=\sum_{k=1}^{8} f_{k} A_{k}(i, j) \cos \left[w_{k} t-P_{k}(i, j)+\chi_{k}\right]$

where $\eta_{0}$ is the tidal elevation in the open boundary, and $w_{k}$, $A_{k}$, and $P_{k}$ for the normal component of depth-mean currents of the $k^{\text {th }}$ constituent denote the angular velocities, amplitudes, and phases of tidal elevation, respectively. Nodal factors allowing for the 18.6-year variation in amplitude and phase of the constituents are represented by $f_{k}$, while $\chi_{k}$ is the astronomical argument for the real-time tide calculation. In this study, $f_{k}$ and $\chi_{k}$ were fixed to 1.0.

As model input, we used output data from the KMA Regional Data Assimilation and Prediction System (RDAPS) with $30-\mathrm{km}$ intervals over the northwestern Pacific Ocean. We interpolated these data to the storm surge model grid resolution, using 3-hourly sea surface wind and pressure as the forcing input for STORM.

You et al. (2007) compared the sea surface wind patterns between RDAPS and QuikSCAT data. The bias value between model and observation represent less than -0.5 and $-1 \mathrm{~m} \mathrm{~s}^{-1}$ in the summer and winter seasons, respectively. Although sea surface winds by RDAPS are weaker than that of observations, the RDAPS simulates well oceanic parameters around Korean Peninsula.

A storm surge refers to an abnormally high sea level, produced by severe meteorological conditions (Gill 1982). In this model, the storm surge level was defined as the difference between the sea level forced by tides only and the sea level forced by tides and wind. The method of calculation is explained in results section. STORM predicted 48-h storm surge heights for 30 coastal stations at 0000 UTC (Universal Time Coordinated) and 1200 UTC every day.

We compared the storm surge heights observed at 30 tidal stations during the above nine storms with those predicted by STORM, conducting statistical analysis to determine the bias [mean error, Eq. (14)] and root mean square 
error [RMSE, Eq. (15)] between modeled and observed values as follows :

bias $=\frac{1}{N} \sum\left(Y_{m}-Y_{0}\right)$

$\operatorname{RMSE}=\sqrt{\frac{1}{N} \sum\left(Y_{m}-Y_{0}\right)^{2}}$

In the above equations, $N$ is the total number of data, $Y_{m}$ is the predicted sea level, $Y_{0}$ is the observed sea level,
$\overline{Y_{m}}$ is the average predicted sea level, and $\overline{Y_{0}}$ is the average observed sea level.

\section{RESULTS}

We analyzed storm surges for nine typhoons that occurred between 2005 and 2007 (Table 1). Figure 2 shows the best tracks of these typhoons. In 2005, 23 tropical cyclones occurred in the northwestern Pacific Ocean. Among these typhoons, Matsa (0509), Nabi (0514), and Khanun (0515)

Table 1. Typhoons affecting Korea between 2005 and 2007.

\begin{tabular}{|c|c|c|c|c|}
\hline Year & Typhoon & $\begin{array}{c}\text { Duration } \\
\text { (YYYYMMDD) }\end{array}$ & $\underset{(\mathrm{hPa})}{\text { Minimum Pressure }}$ & $\underset{\left(\mathrm{m} \mathrm{s}^{-1}\right)}{\operatorname{Maximum} \text { Wind }}$ \\
\hline \multirow{3}{*}{2005} & MATSA (0509) & $20050731-20050809$ & 955 & 41 \\
\hline & NABI (0514) & $20050829-20050909$ & 925 & 49 \\
\hline & KHANUN (0515) & $20050907-20050915$ & 945 & 43 \\
\hline \multirow{3}{*}{2006} & EWINIAR (0603) & $20060701-20060712$ & 920 & 51 \\
\hline & WUKONG (0610) & $20060813-20060821$ & 980 & 23 \\
\hline & SHANSHAN (0613) & $20060910-20060921$ & 925 & 52 \\
\hline \multirow{3}{*}{2007} & MANYI (0704) & $20070709-20070719$ & 930 & 49 \\
\hline & USAGI (0705) & $20070729-20070806$ & 945 & 45 \\
\hline & NARI (0711) & $20070913-20070919$ & 940 & 48 \\
\hline
\end{tabular}

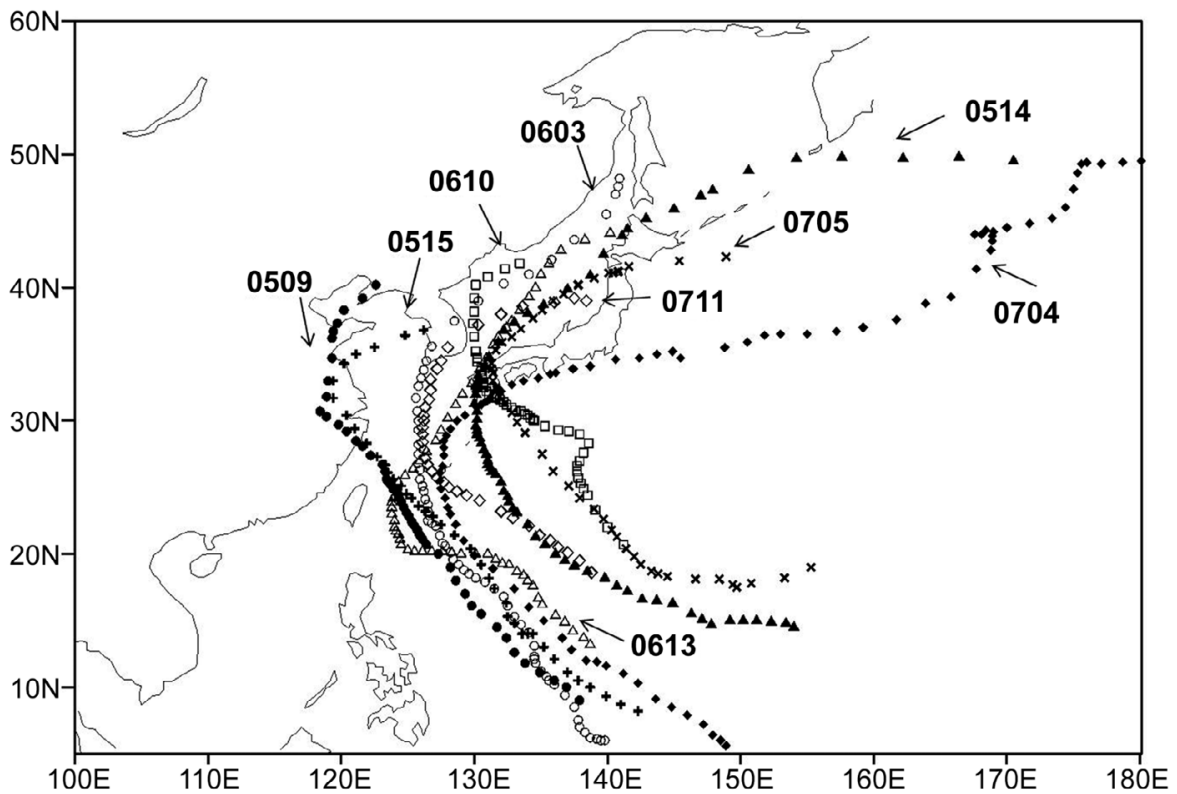

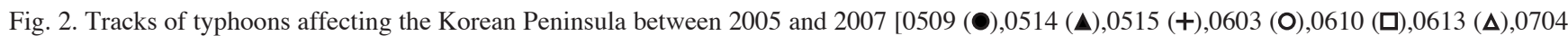
$, 0705(\mathbf{x}), 0711(\diamond)]$. 
approached the Korean Peninsula, with Nabi coming closest. While not making direct landfall on Korea, Typhoons Matsa and Khanun had very similar tracks. Twenty-three tropical cyclones also occurred in the northwestern Pacific Ocean in 2006. Among these, Typhoons Ewiniar (0603), Wukong (0610), and Shanshan (0613) approached the Korean Peninsula. A total of 24 tropical cyclones occurred in 2007, Typhoons Manyi (0704), Usagi (0705), and Nari (0711) affected the Korean Peninsula.

Figure 3 shows the spatial distribution of simulated storm surge elevations from 1200 UTC [2100 KST (Korean Standard Time)] 8 July 2006 to 1200 UTC (2100 KST) 10 July 2006 with 12 hour interval.

Figure 4 shows the spatial distribution of the maximum storm surge height generated by the nine typhoons between 2005 and 2007. Two separate model runs were carried out for each typhoon period. The first run was conducted to generate tides in response to specified open boundary tides consisting of the eight constituents $\left(\mathrm{M}_{2}, \mathrm{~S}_{2}, \mathrm{~K}_{1}, \mathrm{O}_{1}, \mathrm{~K}_{2}, \mathrm{P}_{1}\right.$, $\mathrm{N}_{2}$, and $\mathrm{Q}_{1}$ ) as described by Matsumoto et al. (2000). The second run was conducted to predict tide and storm surges by specifying the wind stress and pressure gradient fields acquired from RDAPS data. The difference between these two results gives the storm surge prediction, including the effects of tidal storm surge-interaction.

The results of storm surges simulations were analyzed using the difference between with and without meteorological forcing. The meteorological effect generally shifts the tide in height as well as in time with respect to the astronomical prediction. For operational use, this concept of storm surge is a more interesting quantity than the residual elevation because it indicates the absolute water level.

Typhoon Matsa in 2005 had maximum storm surges of $65 \mathrm{~cm}$, which first influenced eastern Taiwan and then
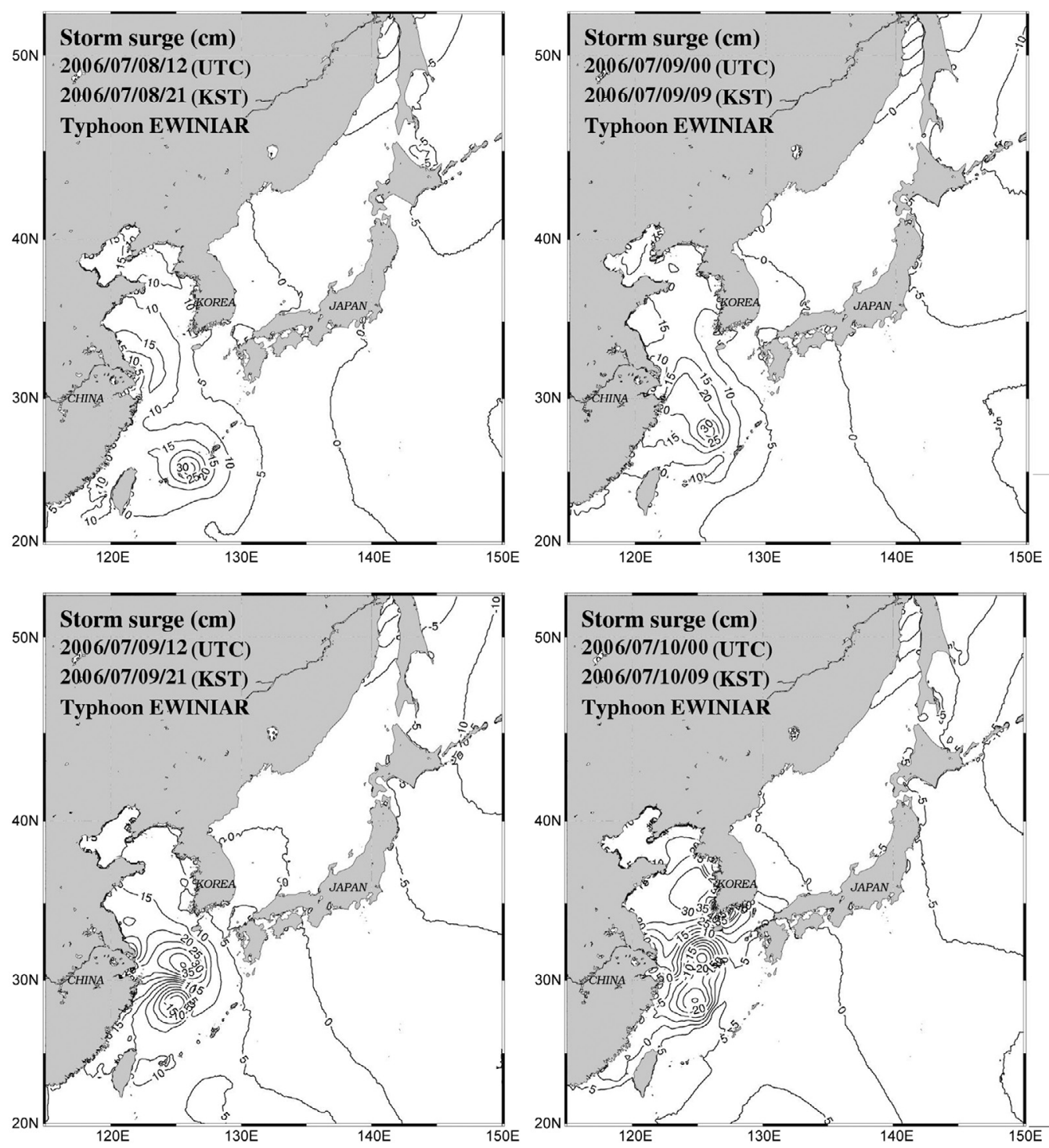

Fig. 3. Predicted storm surge height during Typhoon Ewiniar (12 hour interval). 
(a) 2005 year

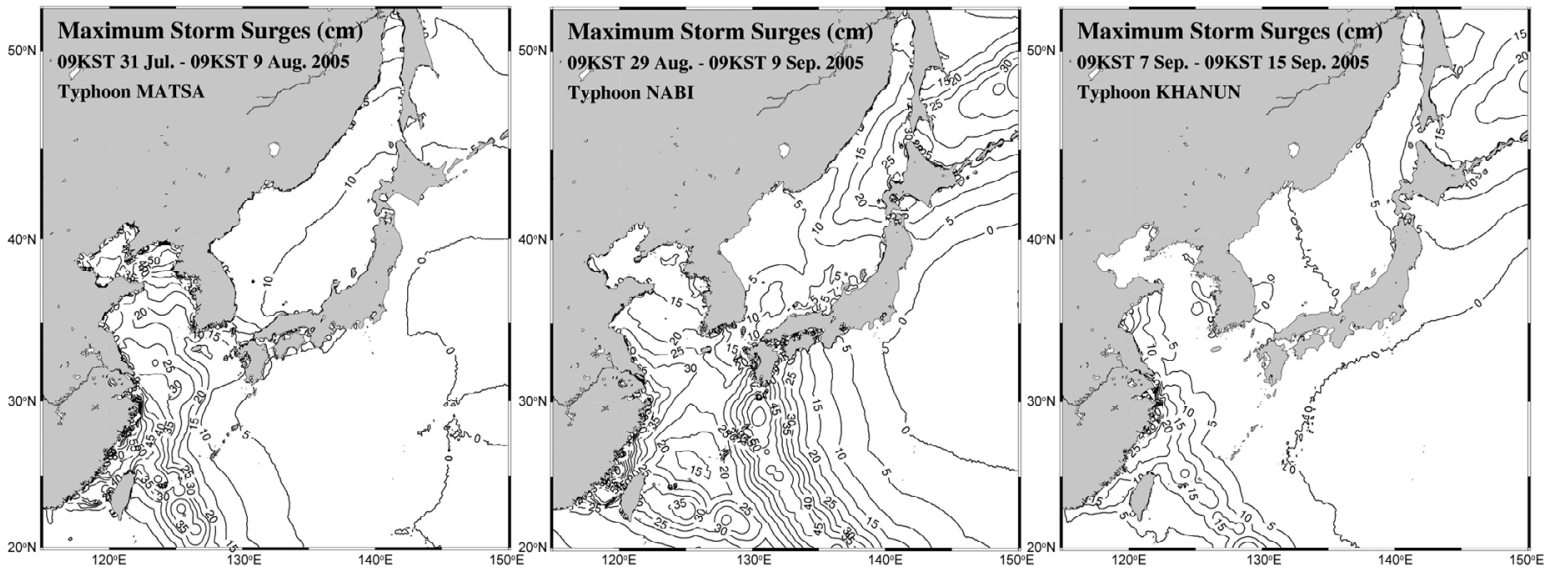

(b) 2006 year

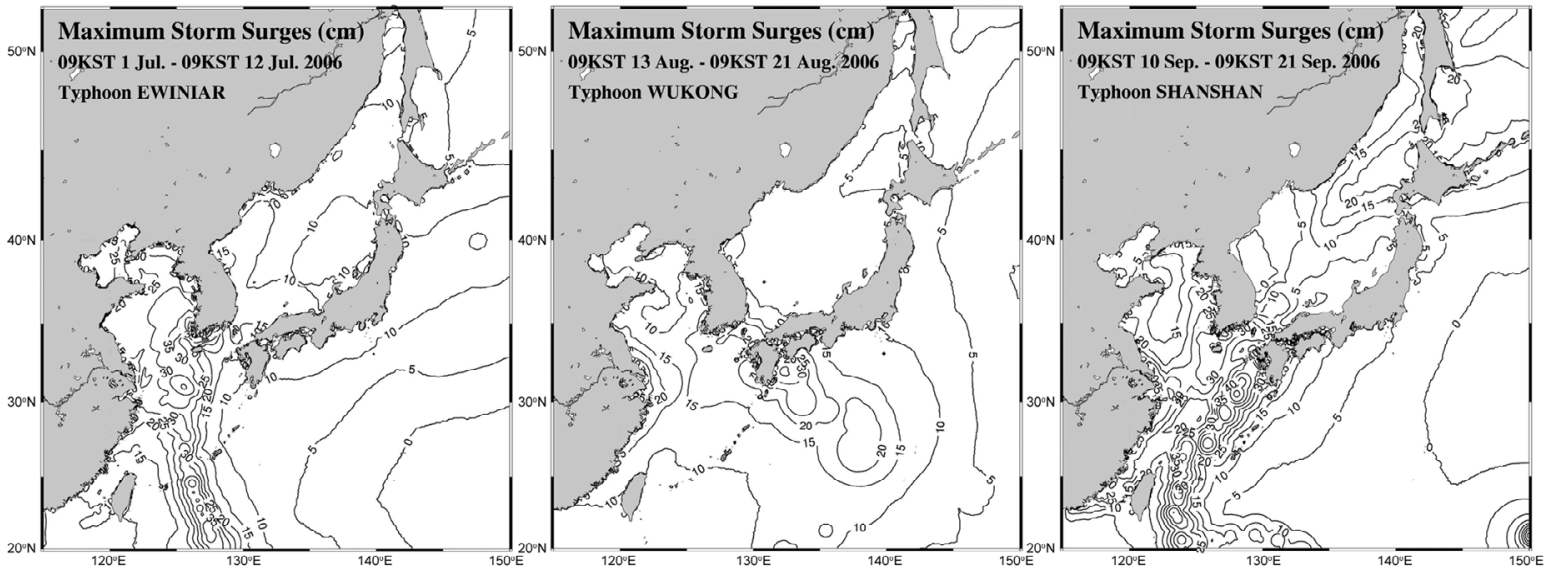

(c) 2007 year

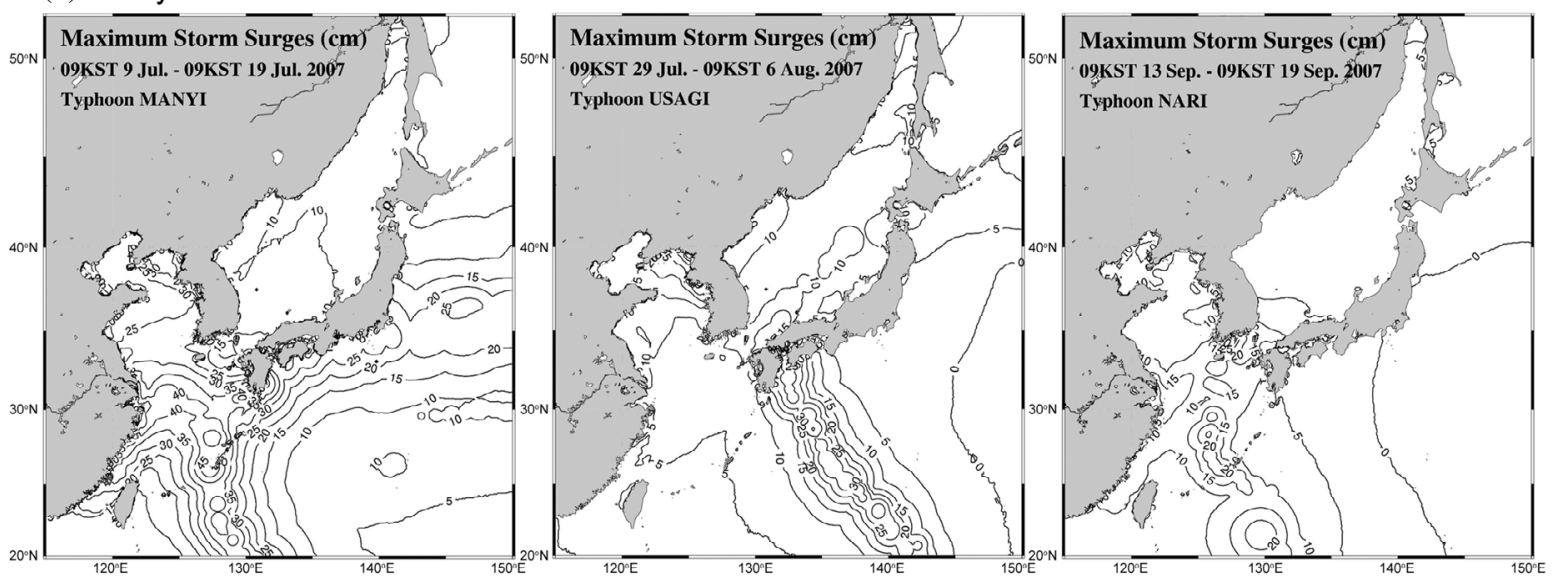

Fig. 4. Maximum storm surge heights for nine typhoons (a) 2005, (b) 2006, and (c) 2007.

struck mainland China. Although Typhoon Matsa did not directly affect the Korean Peninsula, storm surges ranging from 20 to $50 \mathrm{~cm}$ in height occurred on the western coast of Korea. Typhoon Nabi, the typhoon coming closest to Korea in 2005, generated maximum storm surges of $55 \mathrm{~cm}$ at $\mathrm{Ky}$ ushu. After making landfall in Japan, Typhoon Nabi weakened, and the storm surges along the Korean coast were not as high as those at Kyushu. Although Typhoon Khanun had a similar track to that of Typhoon Matsa, the strength and effects of Typhoon Khanun were weaker.

In 2006, Typhoon Ewiniar brought maximum storm surges of $45 \mathrm{~cm}$ to the southern Ryukyu Islands. As Typhoon Ewiniar moved into the Yellow Sea of Korea, it created storm surges of approximately $35 \mathrm{~cm}$ that directly affected the southwestern coast of Korea. When Typhoon Wukong struck southern Kyushu the following month, it generated 
a maximum storm surge of $35 \mathrm{~cm}$ along the southern coast of Japan. After making landfall, the typhoon weakened so that storm surge heights on the southern coast of Korea were approximately $20 \mathrm{~cm}$. Typhoon Shanshan maintained high strength from east of Taiwan to west of Kyushu. As a result, high storm surges of approximately $45 \mathrm{~cm}$ were maintained for a long period.

In 2007, Typhoon Manyi generated high storm surges of $50 \mathrm{~cm}$ in the northwestern Pacific Ocean, which were maintained around the Ryukyu Islands. These strong storm surges considerably influenced most regions of the East China Sea. Typhoon Usagi generated storm surges of approximately $30 \mathrm{~cm}$ in southern Japan. However, as Typhoon Usagi decreased rapidly in strength, storm surge heights fell to approximately $10-15 \mathrm{~cm}$. In the case of Typhoon Nari, storm surges of approximately $20 \mathrm{~cm}$ impacted the southern Ryukyu Islands. The prediction system also simulated storm surges of approximately $20 \mathrm{~cm}$ for the southwestern coast of Korea. However, at this time, the RDAPS data did not accurately represent the strength of Typhoon Nari. As the RDAPS results are the input data for the storm surge prediction system, the simulated storm surge patterns was much smaller than those observed from coastal stations. These results will be discussed in Fig. 7.

Figures 5 through 7 present time-series comparisons between modeled and observed storm surges, excluding astronomical components, at selected coastal stations for nine typhoons. Observed storm surge heights were defined by observed sea level minus calculated tidal level, where tidal elevations were calculated using 64 harmonic constituents.

Table 2 and Fig. 8 show statistical comparisons between predicted and observed surges for the nine typhoons at the following 30 tidal stations: Incheon (INCH), Pyeongtaek (PYOY), Daesan (DAES), Anheung (ANHG), Boryeong (BORG), Janghang (JANH), Gunsan-out (KSOT), Wido (WIDO), Yeonggwang (YONG), Mokpo (MOKP), Daeheuksan-do (DAEH), Jindo (JIND), Chuja-do (CHUJ), Wando (WAND), Geomun-do (KOMU), Goheung (GOHG), Yeosu (YOSU), Tongyeong (TONY), Masan (MASN), Busan (BUSN), Jeju (JEJU), Mosulpo (MOSL), Seogwipo (SOGW), Seongsanpo (SEOS), Ulsan (ULSN), Pohang (POHA), Hupo (HUPO), Mukho (MUKH), Sokcho (SOKC), and Ulleung-do (ULEU). We computed the bias (mean error) and RMSE between the modeled and observed results for the nine typhoon periods. Insufficient observational data or abnormal data caused by observational error were excluded manually.

During Typhoon Matsa, the bias between predicted and observed storm surges at most stations was positive, indicating that simulated storm surges were higher than the observed surges. In contrast, negative bias was shown for Typhoons Nabi and Khanun, indicating that predicted storm surges were lower than observed surges (Fig. 5).

While western stations showed somewhat higher bias values than did southern and eastern stations for Typhoon Matsa, during Typhoons Nabi and Khanun, the southern and eastern stations showed higher bias values than the western stations. The largest bias values (average: -12.06) for 2005 were found for Typhoon Khanun.

In the case of Typhoon Matsa, the maximum bias and RMSE were $5.95 \mathrm{~cm}$ at Mokpo station and $13.44 \mathrm{~cm}$ at Incheon station, respectively. Typhoon Matsa struck mainland China (Fig. 2) and indirectly influenced the Yellow Sea. As a result, negative storm surges could be found on the western coast of Korea. During the period of Typhoon Matsa, the average bias and RMSE between the model estimations and observations were 3.54 and $7.72 \mathrm{~cm}$, respectively.

The maximum bias and RMSE for Typhoon Nabi were $-9.89 \mathrm{~cm}$ at Tongyeong station and $15 \mathrm{~cm}$ at Incheon station, respectively. Negative bias was found at all stations during Typhoon Nabi. As Typhoon Nabi approached the Korean Peninsula, large-amplitude storm surges were observed on the western coast of Korea. The model could not predict the observed short-period features of storm surges (Fig. 5). As Typhoon Nabi approached, large storm surges of approximately $50 \mathrm{~cm}$ were observed along the southern coast of Korea, and the model also predicted similar storm surge peak patterns at that time. However, the model could not reproduce absolute storm surges values at southern stations, such as Wando, Geomun-do, Jeju, and Seongsanpo. The averaged bias and RMSE values were -6.14 and $11.41 \mathrm{~cm}$, respectively.

Among the typhoons of 2005, Khanun showed the largest bias and RMSE values. The track of Typhoon Khanun was very similar to that of Typhoon Matsa, which indirectly affected the Yellow Sea. However, the predicted storm surge heights for Typhoon Khanun were very low compared to the observed heights. The bias and RMSE at Pohang station were -17.24 and $18.30 \mathrm{~cm}$, respectively, with an average bias of $-12.06 \mathrm{~cm}$ and RMSE of $14.61 \mathrm{~cm}$.

In 2006, positive bias (i.e., storm surges higher in the model than in the observations) was found for Typhoon Ewiniar, while negative bias was indicated for Typhoons Wukong and Shanshan, although with values lower than those found in 2005

For Typhoon Ewiniar, there was no large difference in bias value among stations. For example, the maximum bias was $9.16 \mathrm{~cm}$ at Mosulpo station, and the minimum bias was $3.14 \mathrm{~cm}$ at Ulsan station. The averaged bias for all stations was $6.92 \mathrm{~cm}$. The RMSE was somewhat high at Gunsan-out $(20.16 \mathrm{~cm})$ and Janghang $(19.30 \mathrm{~cm})$ stations. Stations along the eastern coast showed low RMSE in comparison to other stations; the averaged RMSE for all stations was $12.00 \mathrm{~cm}$. As indicated in Fig. 6, the modeled storm surges did not accurately produce the large variation in storm surges generated by the approach of Typhoon Ewiniar along the western coast, such as at stations Incheon, Pyeongtaek, Gunsan-out, and Yeonggwang. While the model accurately simulated the 
(a) Matsa
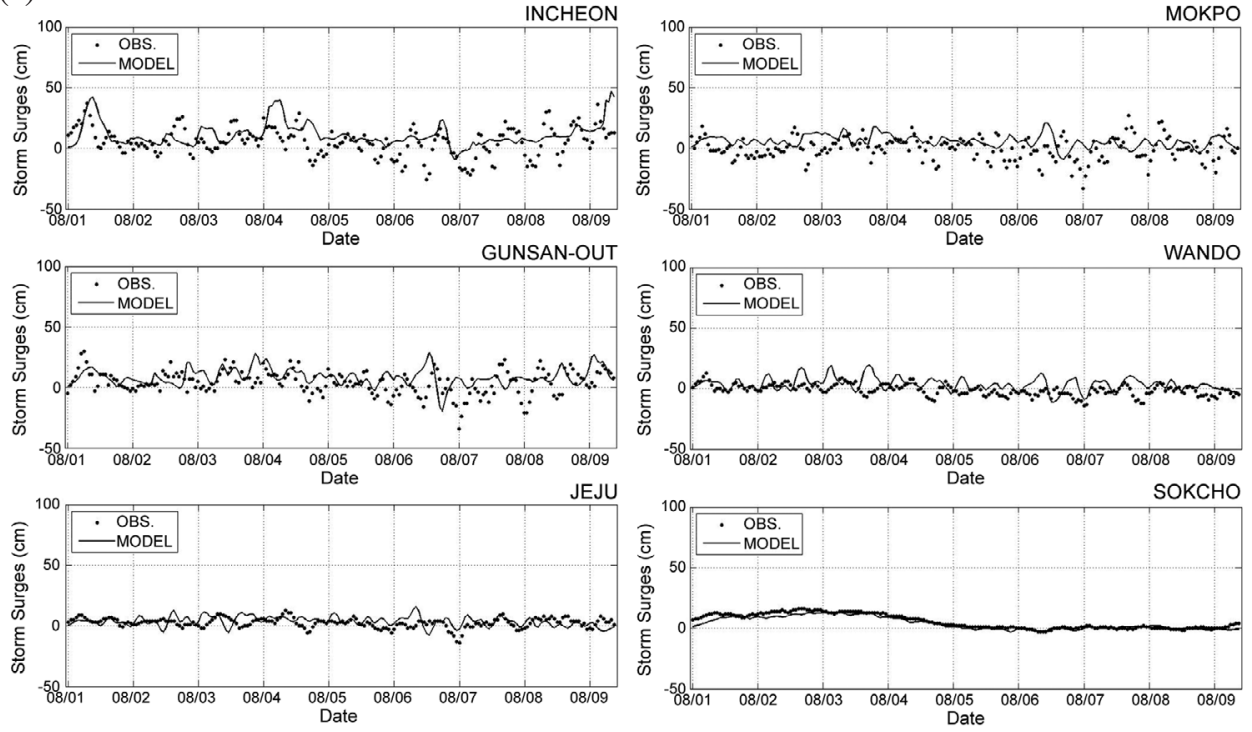

(b) Nabi
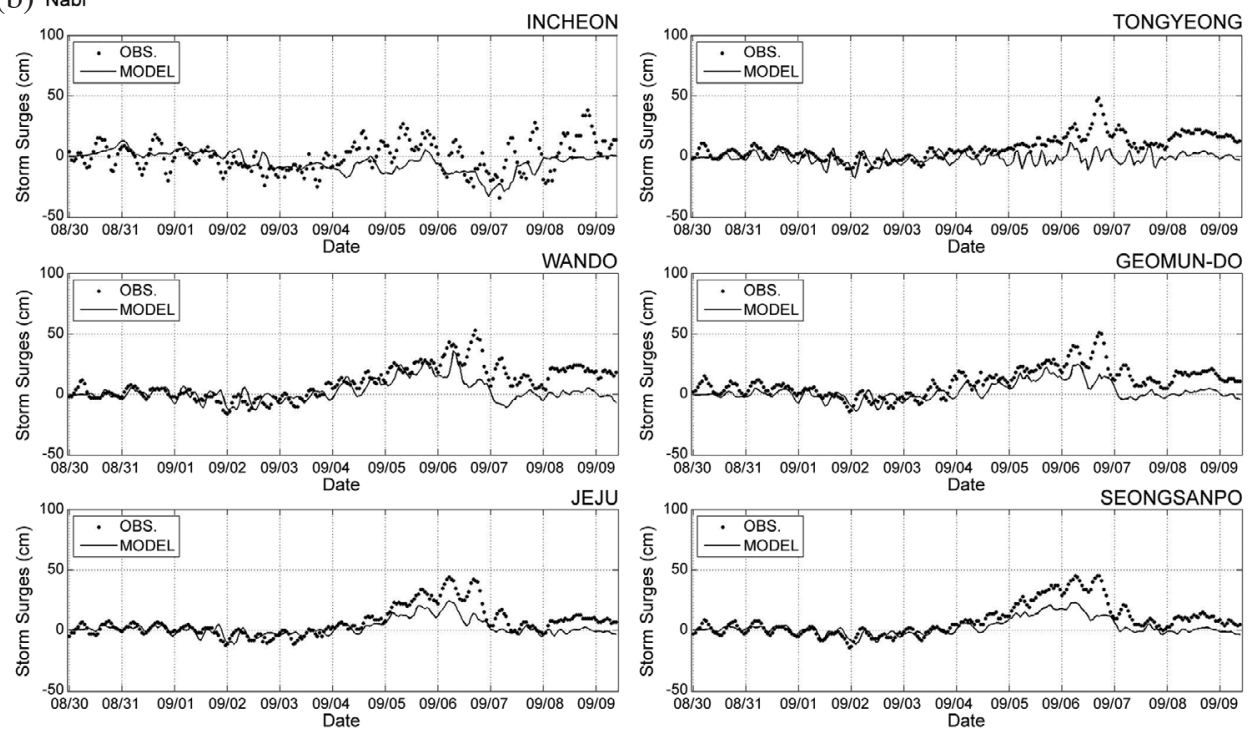

(c) Khanun
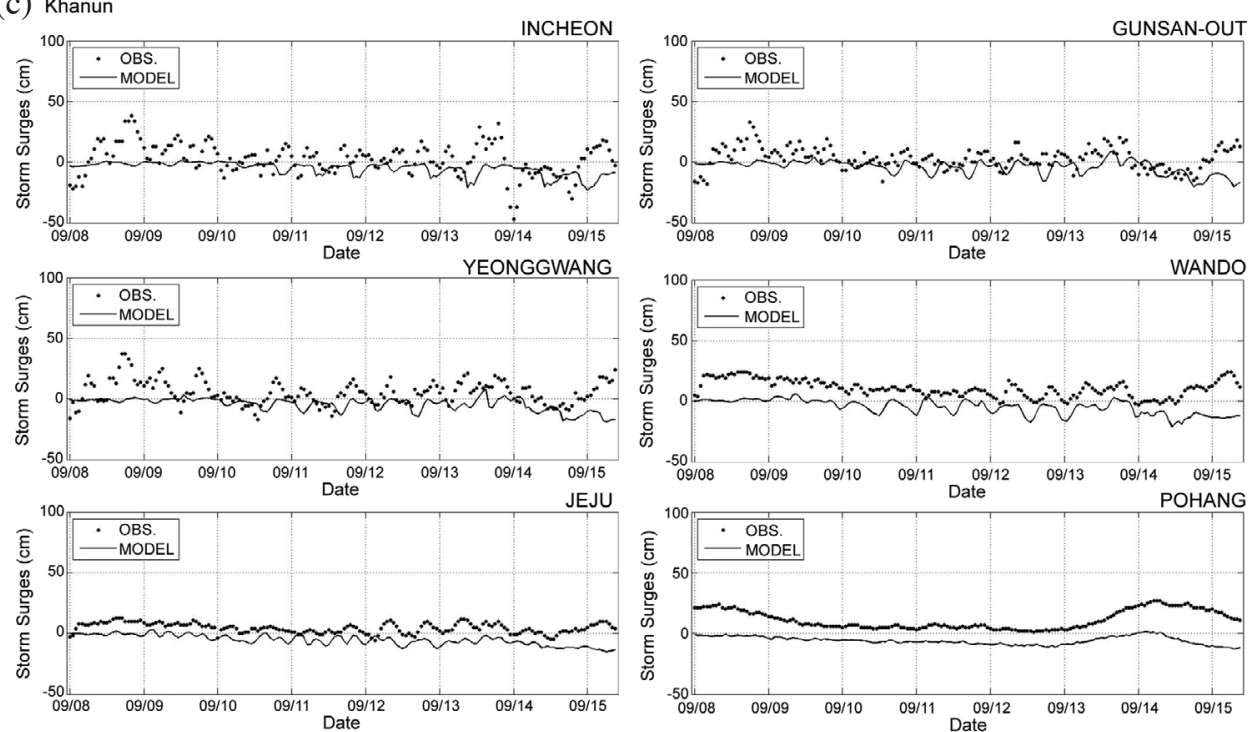

Fig. 5. Time series of the observed and computed storm surges at tidal stations during Typhoons (a) Matsa, (b) Nabi, and (c) Khanun in 2005. (The black line indicates storm surges predicted by the model. The red line indicates storm surges observed at tidal stations). 
(a) Ewiniar

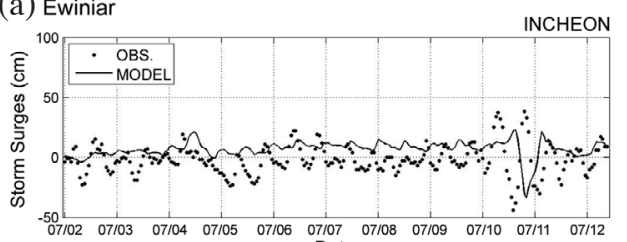

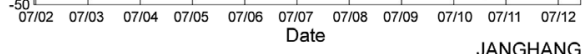
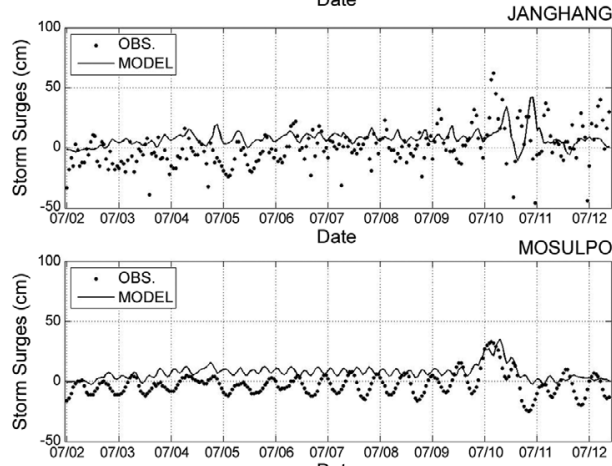

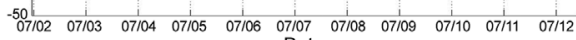

(b) Wukong
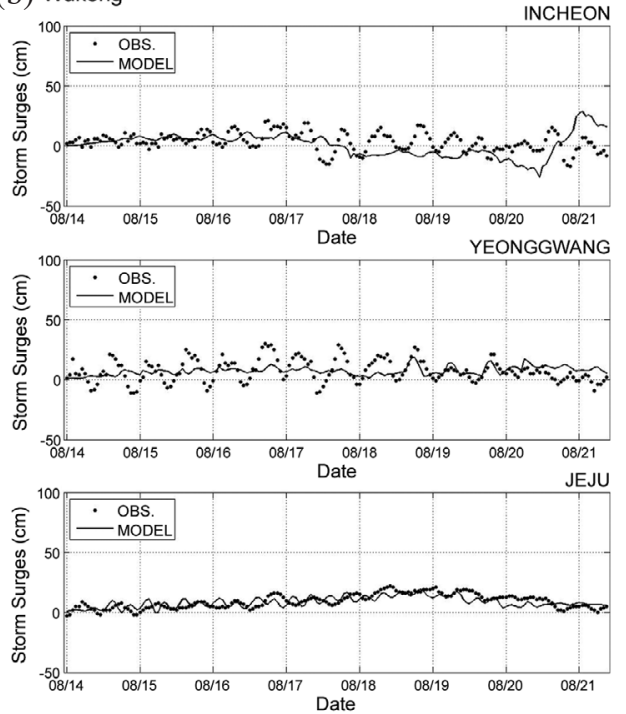

(c) Shanshan
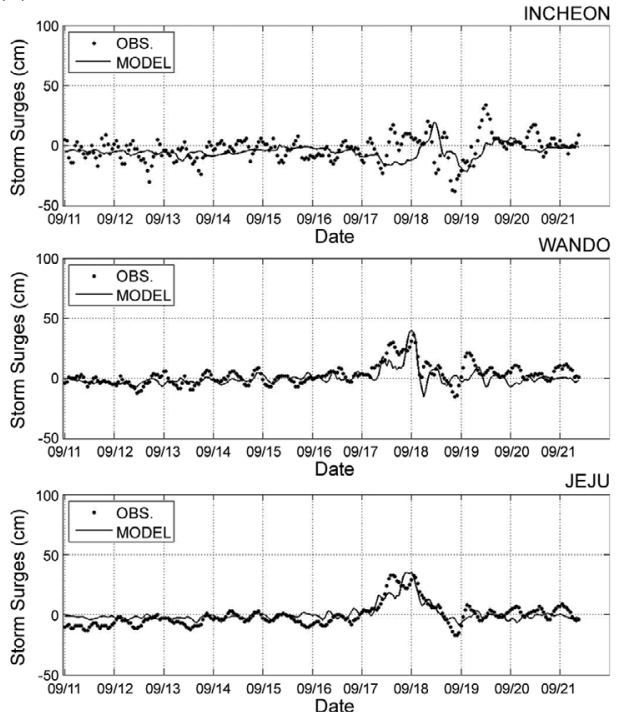
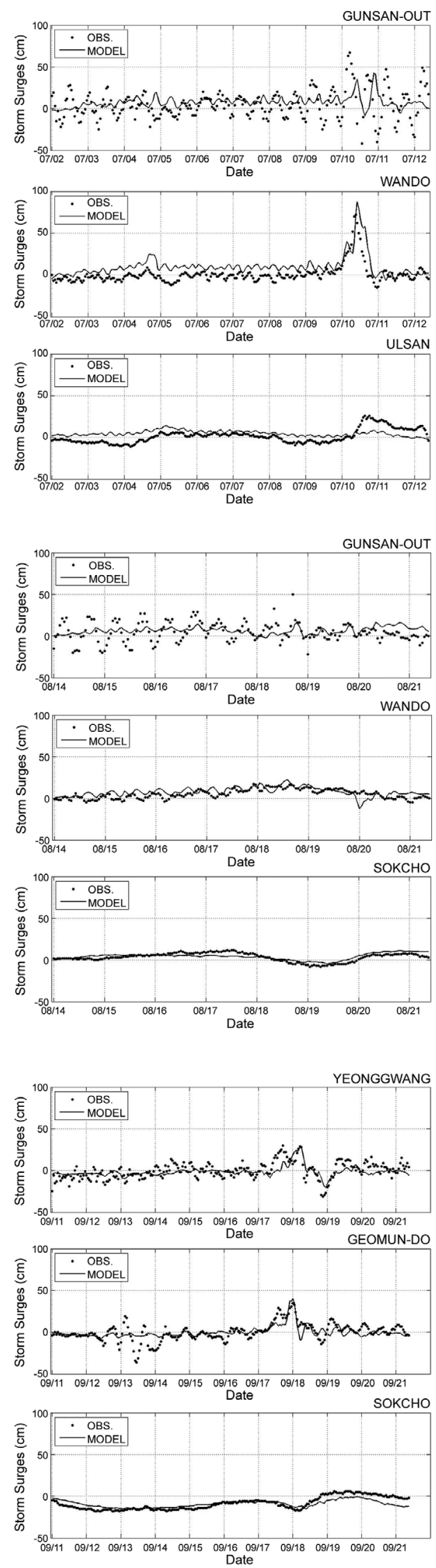

Fig. 6. Time series of the observed and computed storm surges at tidal stations during Typhoons (a) Ewiniar, (b) Wukong, and (c) Shanshan in 2006. (The black line indicates storm surges predicted by the model. The red line indicates storm surges observed at tidal stations). 
(a) Manyi
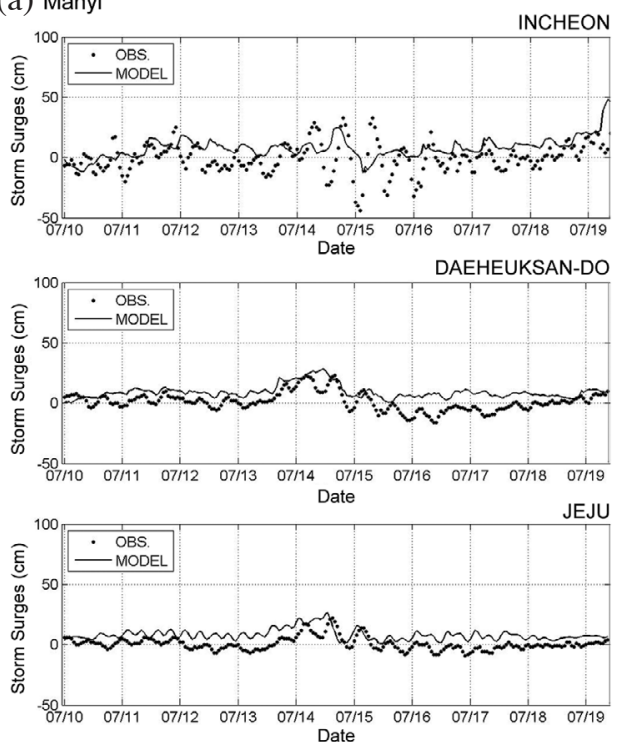

(b) Usagi
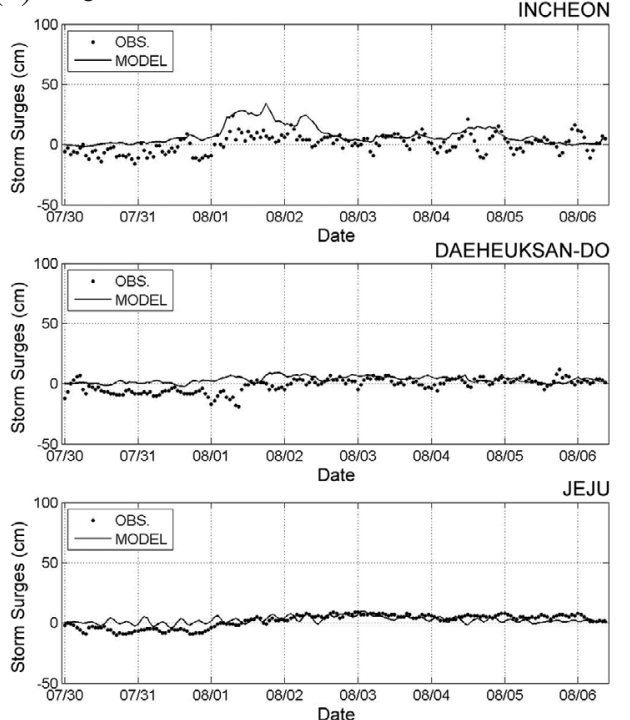

(c) Nari
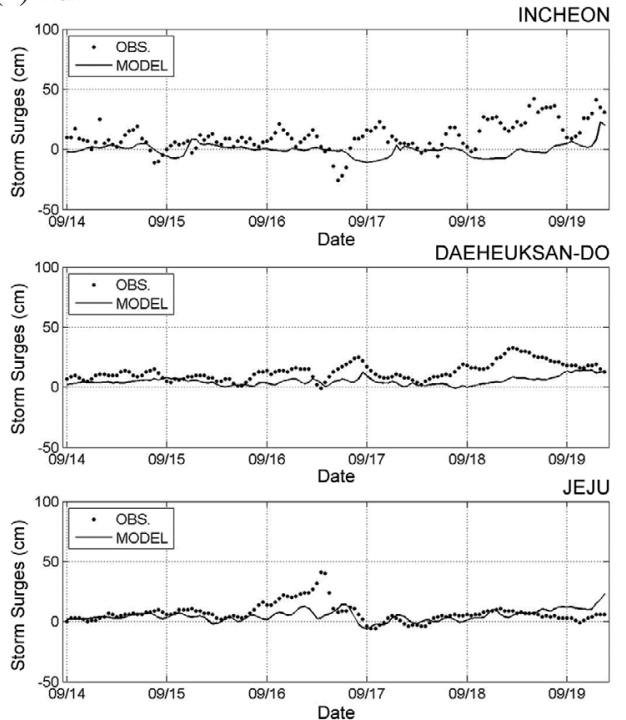
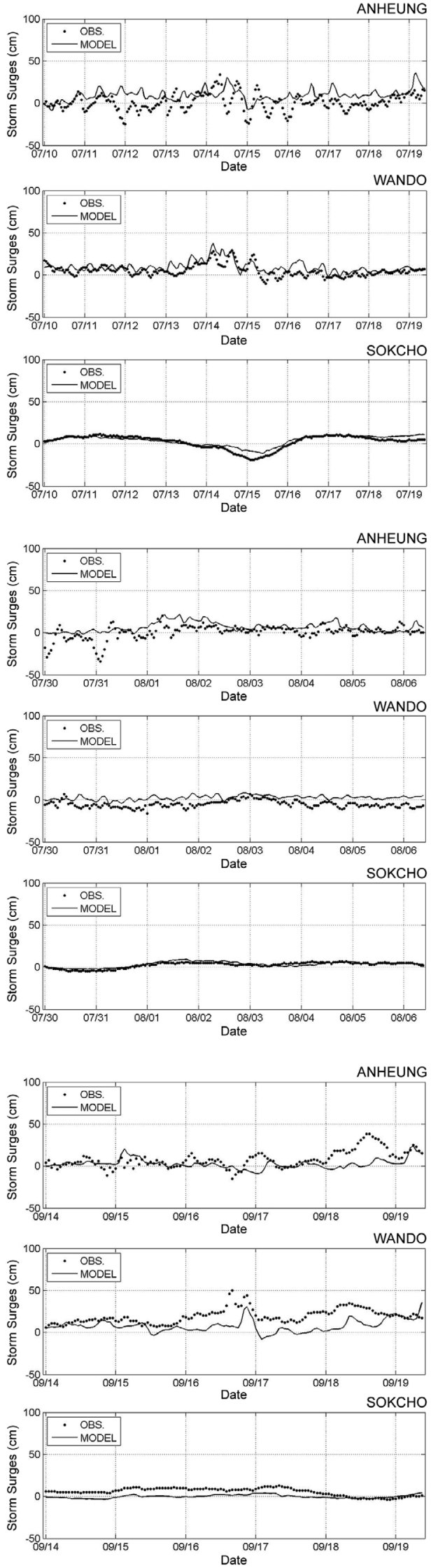

Fig. 7. Time series of the observed and computed storm surges at tidal stations during the period of Typhoons (a) Manyi, (b) Usagi, and (c) Nari in 2007. (The black line indicates storm surges predicted by the model. The red line indicates storm surges observed at tidal stations). 
high storm surge peak of approximately $70 \mathrm{~cm}$ at Wando station, it overestimated storm surge peaks along the southern and eastern coasts.

For Typhoon Wukong, the averaged bias was approximately $-0.43 \mathrm{~cm}$, which was the lowest value among the nine typhoons studied. Typhoon Wukong passed Kyushu and affected its southeastern area, but this typhoon was weak and induced only low storm surges. The bias showed no variation among stations, and the averaged RMSE was approximately $8.32 \mathrm{~cm}$.

Similar to the results for Typhoon Wukong, the statistics for Typhoon Shanshan showed no variations among stations. Averaged bias was also small (approximately $-1.76 \mathrm{~cm}$ ), and RMSE values were low (less than $10 \mathrm{~cm}$ ), except at western stations. The averaged RMSE was about $8.63 \mathrm{~cm}$.

In 2007, Typhoons Manyi, Usagi, and Nari approached the Korean Peninsula. Modeled storm surges exceeded observed values during Typhoons Manyi and Usagi. However, the model underestimated surges induced by Typhoon Nari, the strongest typhoon in 2007. Comparison of the maximum storm surges for Typhoon Nari revealed differences between the modeled and observed values. As mentioned above, boundary conditions (sea winds and sea level pressure) for the storm surge model were provided by the RDAPS, an operational weather forecast system of the KMA. However, the strength of typhoon simulated by the RDAPS differed markedly from the observed patterns during Typhoon Nari. The model results showed that the typhoon struck the southern coast of Korea; nevertheless, there were large differences between modeled and observed storm surges.

Statistical analysis for Typhoon Manyi showed a maximum bias of $8.90 \mathrm{~cm}$ at the Janghang station and an averaged bias of $4.69 \mathrm{~cm}$. RMSEs were largest along the western coast and became small along the southern and eastern coasts for Typhoons Manyi and Usagi. The averaged bias and RMSE for Typhoon Usagi were 3.34 and $6.78 \mathrm{~cm}$, respectively. As mentioned above, for the case of Typhoon Nari, the model underestimated storm surges due to errors in the predicted typhoon strength. The averaged bias and RMSE were -7.99 and $12.19 \mathrm{~cm}$, respectively.

\section{CONCLUSIONS}

This study was performed to examine the characteristics of storm surges associated with nine typhoons between 2005 and 2007 by comparing operational storm surge model results and observations from 30 tidal stations. The model overestimated or underestimated storm surges according to the input boundary condition and the typhoon characteristics. The results (bias) showed that in cases in which the model overestimated (underestimated) storm surge heights, overestimation (underestimation) tended to occur at all coastal stations. The maximum positive bias of $6.92 \mathrm{~cm}$ was found for Typhoon Ewiniar (2006), while the maximum negative bias of $-12.06 \mathrm{~cm}$ was shown for Typhoon Khanun (2005). The RMSE results showed maximum and minimum errors of 14.61 and $6.78 \mathrm{~cm}$ for Typhoons Khanun (2005) and Usagi (2007), respectively. The total averaged RMSE for the nine typhoons studied here was approximately $10.2 \mathrm{~cm}$

Large differences in modeled and observed storm surge heights were observed in two types of cases: a very weak typhoon causing very low storm surges, such as Typhoon Khanun in 2005, or errors in typhoon strength predicted by the RDAPS led to errors in storm surge predictions such as Typhoon Nari in 2007.

Generally, off-shore storm surges can be generated usually by an inverted barometric effect and, not by a wind setup due to the deep water depth. However, coastal storm surges pattern must be affected by the water depth. The complex coastline is characterized by many islands and shallow water depths along the western and southern coast of Korea. Also, exposure and flooding in the wide tidal flat have occurred repeatedly along the Korean coast. As a results, storm surges adjacent to Korean coastal regions show complex spatial variations.

Although the model successfully reproduced storm surge fluctuations for nine Typhoon events, it is still necessary to improve the accuracy of a model for prediction. To more accurately predict storm surges, it is necessary to verify the model input data, such as sea wind and sea level pressure, in advance. At present, RDAPS data with horizontal resolution of $30 \mathrm{~km}$ are used as forcing of the boundary condition of the operational storm surge model. Prediction

Table 2. Mean bias and RMSE storm surge statistics (in $\mathrm{cm}$ ) for typhoons between 2005 and 2007. A positive (negative) bias indicates overestimation (underestimation) by the model.

\begin{tabular}{lcc}
\hline & Bias & RMSE \\
\hline Matsa (0509) & 3.54 & 7.72 \\
Nabi (0514) & -6.14 & 11.41 \\
Khanun (0515) & -12.06 & 14.61 \\
Ewiniar (0603) & 6.92 & 12.00 \\
Wukong (0610) & -0.43 & 8.32 \\
Shanshan (0613) & -1.76 & 8.63 \\
Manyi (0704) & 4.69 & 8.95 \\
Usagi (0705) & 3.34 & 6.78 \\
Nari (0711) & -7.99 & 12.19 \\
\hline
\end{tabular}


(a) 2005 year

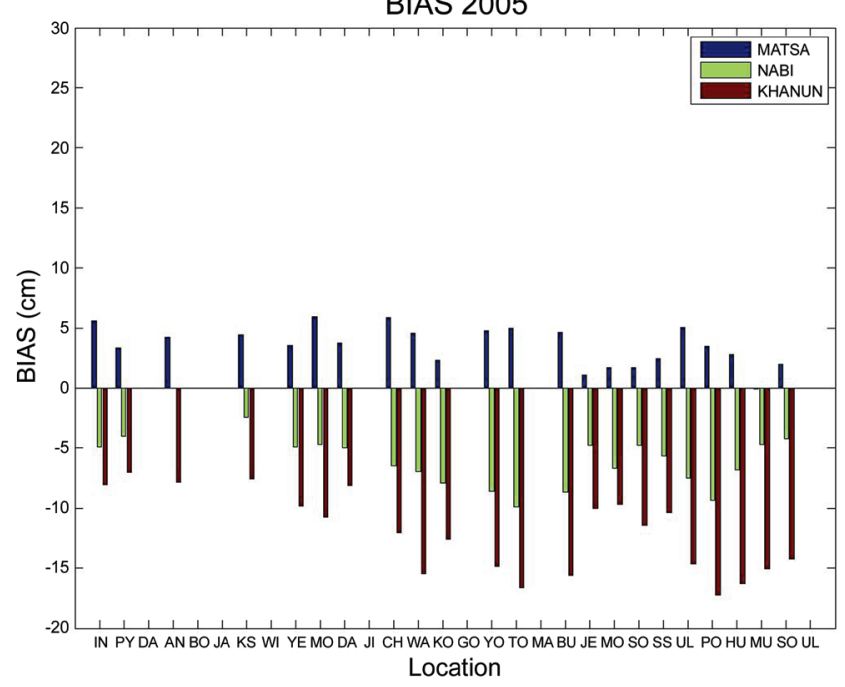

(b) 2006 year

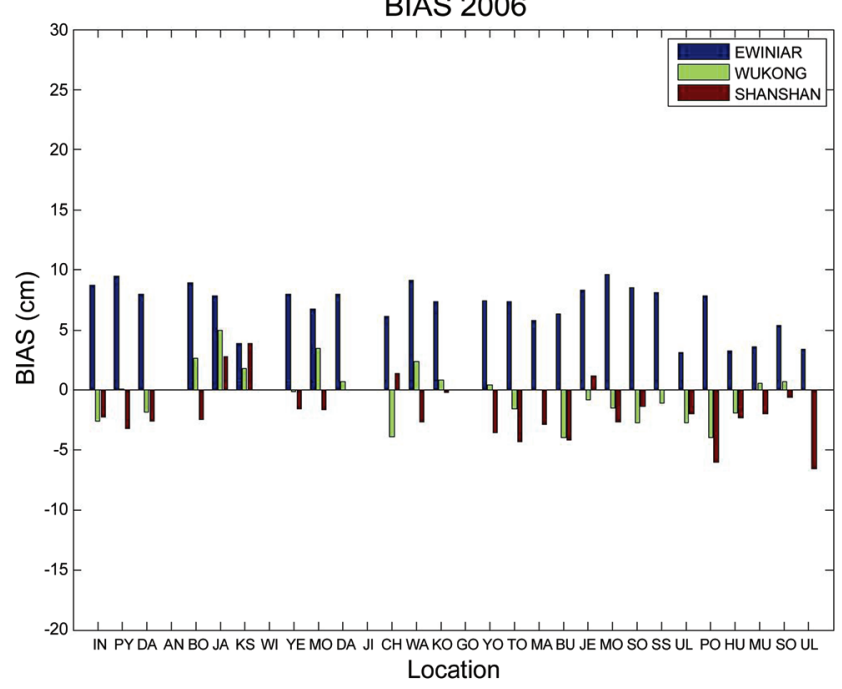

(c) 2007 year

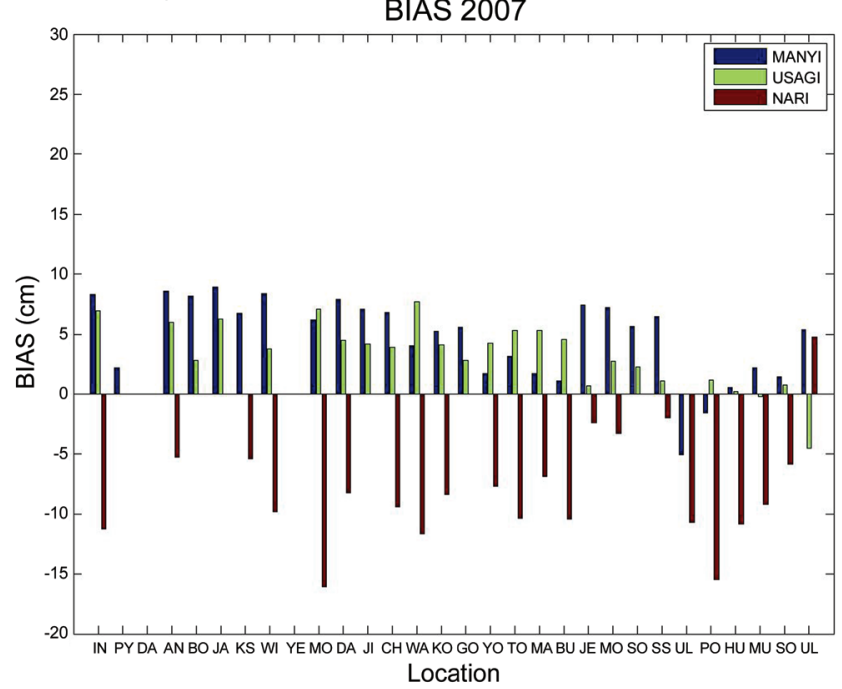

RMSE 2005

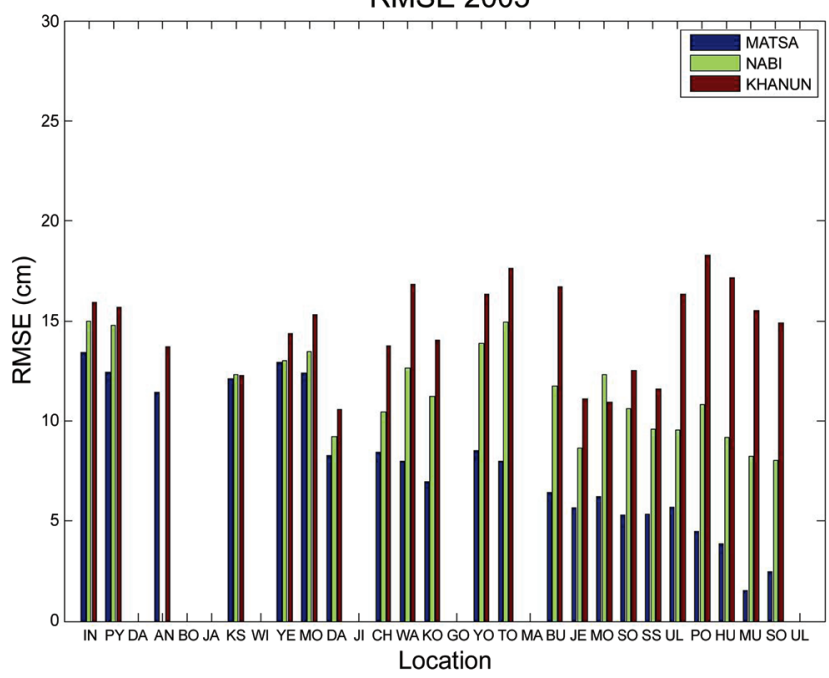

RMSE 2006

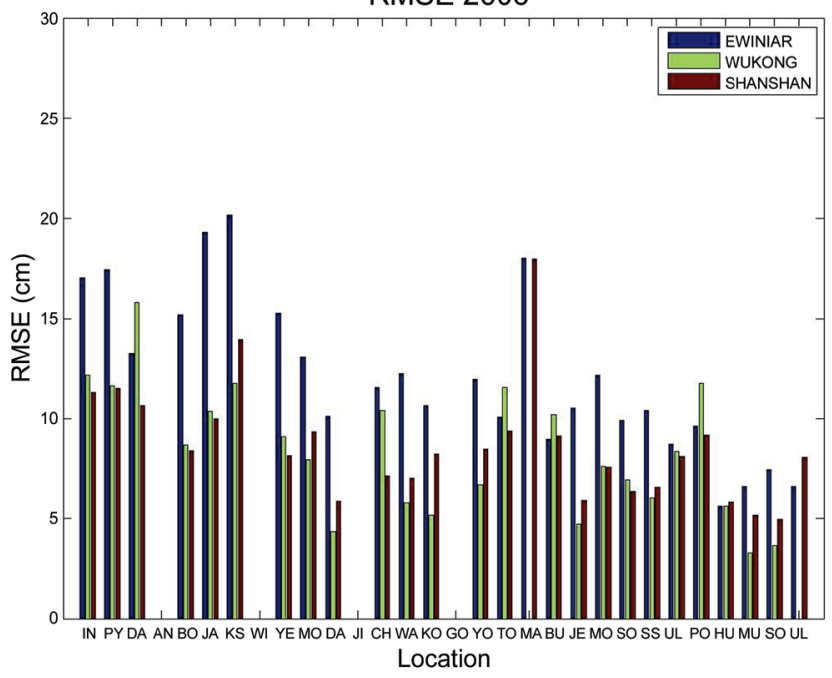

RMSE 2007

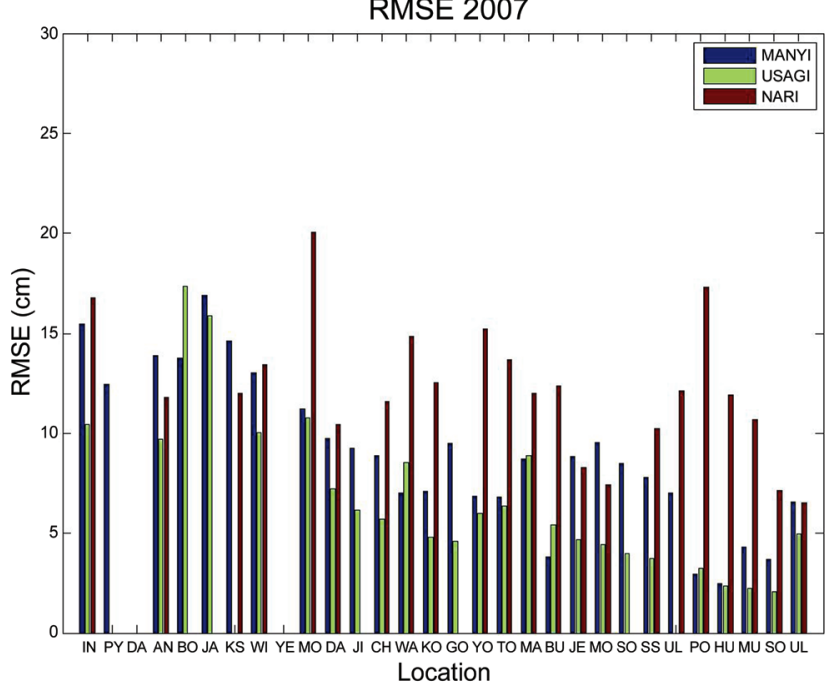

Fig. 8. Variations of bias and RMSE between modeled and observed storm surges caused by typhoons in (a) 2005, (b) 2006 and (c) 2007. 
errors in RDAPS data, such as errors in sea winds and typhoon tracks, have a direct effect on the result of the storm surge model. More precise input data will improve prediction accuracy. In addition, more advanced models, including high-resolution nesting models, should be developed to predict storm surges in complex coastal regions of the Korean Peninsula.

In the near future, a high horizontal weather forecast model, called the Unified Model (UM), will be applied to the operational forecasting system instead of the RDAPS model. The higher resolution input data should enhance the accuracy of storm surge predictions. In addition, a more advanced model is needed to produce high-resolution predictions of storm surges along the complex coastline of Korea.

ACKNOWLEDGEMENTS This research was carried out as a part of the "Valuation of Precision Improvement of Surge Prediction System" and "Research for the Meteorological Observation Technology and its Application" research supported by a NIMR/KMA and KORDI NAP collaboration project.

\section{REFERENCES}

Cha, E. J., K. H. Lee, Y. H. Park, J. S. Park, J. K. Shim, H. J. In, H. D. Yoo, H. J. Kwon, and D. S. Shin, 2007: Characteristics of typhoon in 2006 and improvement of typhoon forecast. Atmosphere, 17, 299-314.

Cha, E. J., Y. H. Park, and H. J. Kwon, 2008: Characteristics of tropical cyclones over the western North Pacific in 2007. Atmosphere, 18, 183-197.

Choi, B. H., 1986: Surge hindcast in the East China Sea. Prog. Oceanogr., 17, 177-192, doi: 10.1016/00796611(86)90043-1. [Link]

Chu, G. S., 1987: On the storm surges and tsunami occurred in the coast of Korea, Hydrographic Office, Republic of Korea, $153 \mathrm{pp}$.

Gill, A. E., 1982: Atmosphere-Ocean Dynamics, Volume 30, Academic Press, 662 pp, doi: 10.1016/S00746142(08)60025-X. [Link]
Hong, C. H. and J. H. Yoon, 2003: A three-dimensional numerical simulation of Typhoon Holly in the northwestern Pacific Ocean. J. Geophys. Res., 108, 3282, doi: 10.1029/2002JC001563. [Link]

Hwang, J. P., 1971: On the variation of sea level due to meteorological disturbances of the coast of Korea, Storm surges caused by Typhoon Billie, 1970, on the west and south coasts of Korea. J. Oceanol. Soc. Korea, 6, 92-98.

KMA (Korea Meteorological Administration), 2005: Establishment of research plan for long and short term typhoon and survey of Typhoon Center Foundation, KMA, 160 pp.

KMA (Korea Meteorological Administration), 2006: Report for typhoon analysis in 2005, KMA, 38 pp.

KMA (Korea Meteorological Administration), 2007: Report for typhoon analysis in 2006, $147 \mathrm{pp}$.

Matsumoto, K., T. Takanezawa, and M. Ooe, 2000: Ocean tide models developed by assimilating TOPEX/POSEIDON altimetry data into hydrodynamic model: A global model and a regional model around Japan. J. Oceanogr., 56, 567-581, doi: 10.1023/A:1011157212596. [Link]

Mellor, G. L., 1998: Users Guide for a Three Dimensional Primitive Equation, Numerical Model, Program in Atmospheric and Oceanic Sciences, Princeton University, Princeton, New Jersey, USA, 56 pp.

Oh, I. S. and S. I. Kim, 1990: Numerical simulations of the storm surges in the seas around Korea. J. Oceanol. Soc. Korea, 25, 161-181.

Oh, I. S., S. I. Kim, and J. H. Bong, 1988: Storm surges by the typhoons passing through the South Sea of Korea. J. Korea Met. Soc., 24, 72-84.

You, S. H., J. W. Seo, H. M. Lee, D. U. Lee, and Y. H. Youn, 2005: The development of high resolution regional storm surges prediction model, 2005 Spring Meeting of the Korean Meteorological Society, 390-391.

You, S. H., J. G. Cho, and J. W. Seo, 2007: Comparison of KMA Operational Model RDAPS with QuikSCAT Sea Surface Wind Data. J. Kor. Soc. Coast. Ocean Eng., 19, 467-475. 